Schuler, W. and Weidemann, A. (1935). Hoppe-Seyl. Z. 233, 235.

Seull, C. W. and Rose, W. C. (1930). J. biol. Chem. 89, 109.

Shambaugh, N. F., Lewis, H. B. and Tourtelotte, D. (1931). J. biol. Chem. 92, 499 ,

Simmonds, S. and Du Vigneaud, V. (1942). J. biol. Chem. 146, 685.

Stetten, D. $(1941,1)$. J. biol. Chem. 138, 437.

Stetten, D. (1941, 2). J. biol. Chem. 140, 143.

Stetten, D. (1942). J. biol. Chem. 144, 501.

Stewart, C. P. (1925). Biochem. J. 19, 1101.

Sure, B. (1941). J. Nutrit. 22, 491.

Trowell, O. A. (1941). J. Physiol. 100, 432.

Tucker, H. T. and Eckstein, H. C. (1937). J, biol. Chem. 121, 479.

Weichselbaum, T. E. (1935). Quart. J. exp. Physiol. 25, 363.

Weichselbaum, T. E., Weichselbaum, M. B. and Stewart, C. P. (1932). Nature, Lond., 129, 795,

Weiske, H., Schrodt, M. and Dangel, S. V. (1879). Z. Biol. 15, 261.

Werle, E. (1936). Biochem. Z. 288, 293.

Werle, E. (1940). Biochem. Z. 304, 201.

Willcock, E. G. and Hopkins, F. G. (1906-07). J. Physiol. 35, 88.

Wolf, P. A. and Corley, R. C. (1939). Amer. J. Physiol. 127, 589.

Womack, M., Kemmerer, K. S. and Rose, W. C. (1937). J. biol. Chem. 121, 403.

Womack, M. and Rose, W. C. (1934). J. biol. Chem. 107, 449.

Womack, M. and Rose, W. C. (1935-36). J. biol. Chem., 112, 275.

Womack, M. and Rose, W. C. (1936). J. biol. Chem. 116, 381.

Womack, M. and Rose. W. C. (1941). J. biol. Chem. 141, 375.

\title{
The Therapeutic Use of Protein Hydrolysates
}

\section{Dr. A. B. Anderson (Glasgow Royal Infirmary)}

There are several recent reviews dealing with various aspects of the use of protein hydrolysates (Cuthbertson, 1944; Elman, 1944, 1945; Gaunt, 1944), and this paper is to some extent a summary of the present position. No attempt has been made to review the literature completely. The remarks are confined to the work on human beings.

Protein hydrolysates are a very recent addition to the therapeutic armamentarium, and it is surprising that these preparations did not come into use earlier, when one considers the obvious theoretical advantages of the hydrolysates as easily assimilated non-antigenic material, and the fact that various digests of proteins have been used for many years as nutrients for bacterial growth, e.g., a tryptic digest of casein (Cole and Onslow, 1916). It was not until 1938 that a preparation of hydrolysed protein was administered intravenously to human beings by Eilman and Weiner (1939), although in 1889 an alkaline digest of casein had been injected intravenously into animals (Neumeister, 1889).

\section{Indications for Therapy}

The theoretical indications for the use of a protein hydrolysate may be considered to be states of protein deficiency or threatened deficiency following:

(1) Inability to ingest protein food because of some gastro-intestinal disease, e.g., intestinal obstruction or persistent vomiting;

(2) Starvation;

(3) Inability to ingest sufficient protein to make up for excessive loss from the body, e.g., in severe burns;

voL. 4,1946$]$ 
(4) Inability to absorb or digest the protein ingested, e.g., ulcerative colitis, fistulae;

(5) Extreme cases of protein allergy.

These appear to be the main indications, but there are other conditions in which hydrolysates have been used; for example, the use of protein digests reinforced with cystine has been suggested in liver disease (Beattie and Marshall, 1944), but obviously this would only be done in default of a supply of methionine.

\section{Nature of Hydrolysates}

The protein hydrolysates which have been used are either acid hydrolysates refortified with tryptophane, which is destroyed during the hydrolysis, or enzymic digests by trypsin or papain. Casein is the usual protein substrate, but digests of meat, especially papain digests, have been used.

The approximate composition of two of the commercial preparations obtained by enzymic hydrolysis of casein is given in Table 1 .

TABLE 1

Composition of Two Commerctal Enzymic Hydrolysates of Casein

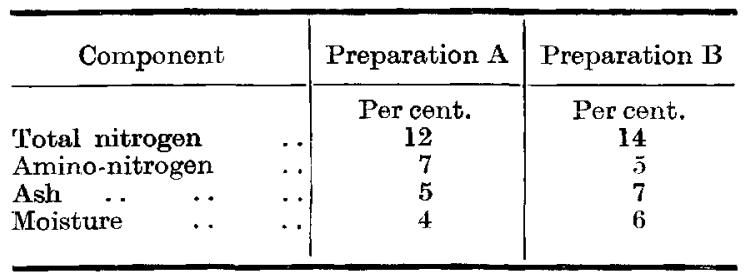

\section{Method of Administration}

The hydrolysates can be administered by the intravenous, subcutaneous, or oral, route. For intravenous administration a 2.5 per cent. solution in water with 5 to 10 per cent. glucose is generally used. Stronger solutions tend to produce thrombosis. The $p H$ of most preparations is in the region of $4 \cdot 5$, and it has been suggested that a solution neutralized to $p \mathrm{H} 6.5$ is more satisfactory, and can be used in greater strength (Elman, Weiner and Bradley, 1942). The solution, which must be free from pyrogens, is given slowly, about one litre at a time over two hours, the rate being adjusted to the reaction of the patient. The untoward reactions which may be observed are nausea and vomiting from too rapid injection, mild pyrogenic reactions, and thrombosis at the site of injection.

It has been suggested on the basis of a fatal case that severe liver damage is a contra-indication to intravenous medication (Hopps and Campbell, 1943). Another fatality associated with intravenous hydrolysate has been reported by Curreri, Hibma and Cohen (1945).

Injection into the bone marrow has also been used successfully (Altshuler, Sahyun, Schneider and Satriano, 1943).

For subcutaneous injection an isotonic solution of 5 per cent. aminoacids and 5 per cent. glucose diluted with an equal quantity of distilled water is used. A contra-indication to subcutaneous administration is 
a very low plasma protein or poor peripheral circulation, as in these conditions the solution will not be absorbed, but remain in situ and absorb water from the tissues (Hartmann, Lawler and Meeker, 1944). These solutions of amino-acids for parenteral use are excellent culture media, and bacterial contamination must be avoided.

The oral route, which is the only one I have used personally, presents some difficulties owing to the nauseating taste of some preparations. The tryptic digests of casein all seem to have an objectionable taste in greater or lesser degree, though the papain digests of meat are quite palatable. The objectionable taste of casein digests cannot be removed by dilution, and it is a mistake to give them in the form of a dilute soup. I have found that the most satisfactory way to give small quantities, if patients find difficulty in taking the solution, is to make up a strong dose of, say, $15 \mathrm{~g}$. of the powder in $2 \mathrm{oz}$. of water, neutralize with $1 \mathrm{~g}$. of sodium bicarbonate, and flavour heavily with aniseed oil. This mixture is swallowed rapidly, and is followed by a draught of water. In this way, $60 \mathrm{~g}$. may be given easily in the day. If a larger intake is desired, and the taste is objectionable, recourse must be had to tube feeding into the stomach or jejunum.

Oral feeding with digests must be supplemented with adequate glucose or other carbohydrate, as in intravenous alimentation, since otherwise the amino-acids may be mobilized to supply energy instead of being used for protein building.

\section{Results of Therapy}

There is a considerable body of evidence on the results of hydrolysate therapy, and it can best be discussed on the basis of the theoretical indications given above.

Hydrolysates have been given intravenously for inability to ingest protein in carcinoma of the stomach and intestinal obstruction both before and after operation, and reports are generally favourable. Elman and Weiner (1939) in their original paper reported two cases of intestinal obstruction and three of carcinoma of the stomach, all of which benefited from intravenous therapy. The hydrolysates were well tolerated, and positive nitrogen balances were obtained. In a later paper, Elman (1942) reported on patients with intestinal obstruction treated with excellent clinical results, some of whom showed actual increase in serum proteins.

Advanced starvation would appear to be a most suitable condition in which to administer the hydrolysate, and first reports were most favourable. In the Bengal famine, Narayanan and Krishnan (1944), and Krishnan, Narayanan and Sankaran (1944) administered a papain digest of meat intravenously to patients in the last stages of starvation, with encouraging clinical results.

In contrast to these findings, the report on the value of hydrolysates in the treatment of cases of extreme starvation from Belsen camp by Vaughan, Dent and Pitt-Rivers (1945) is on the whole unfavourable. Intravenous therapy with hydrolysates was difficult owing to the conditions in the camp, and did not give such good results as those obtained. with serum transfusions. Oral administration of the hydrolysate was unsuccessful, and the material had an unpleasant taste. Tube feeding was not practicable with most of the patients. On the other hand, voL. 4, 1946] 
feeding with skim milk was satisfactory. The authors state that hydrolysates may well prove successful under different circumstances. Lipscomb (1945), in a description of the medical aspects of Belsen camp, states "Protein hydrolysate by mouth was tried instead of skimmed milk for severe cases, but the taste is so nauseating that it was difficult to persuade the patients to take it for more than one day". Of intravenous methods he says "Protein hydrolysate was very little used because a 5 per cent. solution caused phlebitis, and the volume of $2 \cdot 5$ per cent. solution required to introduce sufficient nitrogen increased oedema and ascites and risked overloading". A preliminary report by Burger, Stanstead and Drummond (1945) on starvation in western Holland shows that feeding with "protein food" gave more satisfactory results than oral administration of hydrolysates. The "protein food" consisted of skim milk powder and glucose flavoured with raw or tinned fruit. When an acid hydrolysate of casein was given intravenously, it caused thrombosis, and was discontinued.

The European experience with hydrolysates appeared to be that intravenous alimentation was of some value, but that plasma or serum was better, and that oral administration was of little value. It is possible that failure of the oral route was largely due to the unpleasant taste of the hydrolysate available. More palatable preparations might have given better results.

As an example of protein deficiency due to excessive loss one may take the burnt patient. Here there is general agreement as to the excessive loss of nitrogen after burning (e.g., Lucido, 1940; Cope, Nathanson, Rourke and Wilson, 1943; Taylor, Levenson, Davidson, Browder and Lund, 1943; Anderson and Semeonoff, 1944; Co Tui, Wright, Mulholland, Barcham and Breed, 1944). The administration of hydrolysates either intravenously or by tube feeding to these patients has met with considerable success both in balancing the nitrogen loss and in restoring the level of plasma proteins. A now classical case was described by Taylor et al. (1943), in which a man with a severe burn showing excessive loss of protein with oedema despite a diet containing $130 \mathrm{~g}$. of protein, was given amino-acids by vein and stomach tube up to the extent of $300 \mathrm{~g}$. per day. This forced alimentation resulted in a striking disappearance of the oedema, and a rise in plasma protein. In a recent paper, Co Tui et al. (1944) have for the first time measured the nitrogen loss through exudation from the burned surface by estimating the nitrogen lost into the dressings, and obtained a minimum figure of $5 \mathrm{~g}$. per day in two severely burnt patients. In their patients, with burns involving 10,30 and 50 per cent. of the body surface, feeding of hydrolysate (amigen) and dextrimaltose maintained nitrogen balance, the amount of nitrogen required increasing with the severity of the burn, and, in the case of the 50 per cent. burn, reaching $66 \mathrm{~g}$. of nitrogen per day, which, as the authors point out, is equivalent to $2 \mathrm{~kg}$. of meat, an impossible amount to feed.

The deficiency brought about by inability to digest or absorb protein may be illustrated by ulcerative colitis and gastro-enteritis. In ulcerative colitis, good results have been shown with hydrolysates by Elman and Weiner (1939) and Messinger (1943). In gastro-enteritis in infants, Shohl (1943) has reported that when casein hydrolysate was given the infants had good positive nitrogen balances, but that this was not the case when milk was given. Positive balances were obtained when the 
nitrogen intake was $0.35 \mathrm{~g}$. per $\mathrm{kg}$. bodyweight per day. The value of hydrolysates in treating children is confirmed by Hartmann et al. (1944).

An interesting use of hydrolysates has been described by Hill (1941), who treated 36 infants who were allergic to milk with a food consisting of amino-acids 20 , dextrimaltose 42 , olive oil 18 , starch 10 , brewer's yeast 3 , and mineral salts $6 \cdot 7$, per cent. The infants, all under one year old, were given the food for periods varying from 2 weeks to 3 months. Satisfactory results were obtained in 19 of the children. Food allergy in adults has been treated with a similar food with good results (Olmsted, Harford and Hampton, 1944).

In the treatment of surgical conditions other than the burns described above, hydrolysates have been used successfully for intractable diarrhoea following enterostomy by Elman (1943), and to overcome the postoperative loss of nitrogen by Brunschwig, Clark, and Corbin (1942). These authors concluded that the most important factor in the postoperative loss was the restricted intake of food, combined with the general disturbance caused by the operation. They found that casein digest and glucose given intravenously reduced or prevented this loss. The hypoproteinaemia of "surgical shock" may also be treated with hydrolysates, as well as with plasma or serum transfusions (Elman, 1942).

The return of appetite in cases of severe anorexia has been reported by Messinger (1943) to follow the administration of amino-acids. Altshuler et al. (1943) observed a remarkable clinical improvement in some cases of muscular dystrophy after oral treatment with hydrolysate.

In idiopathic steatorrhoea and coeliac disease there is a gross deficiency in absorption from the gut, particularly of fat, but also of other nutrients, and there is often evidence of impaired digestion of protein as shown by the presence of undigested muscle fibres in the stools. These diseases would appear to be a suitable field for hydrolysate therapy. Satisfactory results from the treatment of coeliac disease in children with papain digest have been described by Adamson and Lewes (1944).

\section{Personal Experience}

My own experience has been confined to oral administration in four patients, two of whom were adults with steatorrhoea and two, adolescents who were coeliac dwarfs. When the work was started, commercial preparations of casein digests were not available, as the whole output was required for relief work in Europe. Small quantities of papain digests of lean beef were therefore prepared in the laboratory by the method described by Adamson and Lewes (1944). The product was found to be very satisfactory from the point of view of palatability, but the amount which could be prepared was limited. Commercial preparations of enzymic digests of casein later became available, and could be given in large amounts. With these casein digests the problem of the objectionable taste was encountered, and was finally solved by the method described above.

Previous work on this type of patient had shown that, owing to the peculiar conditions in the intestine, it was not possible to obtain a satisfactory measure of the nitrogen balance unless the collection of excreta was carried out over very long periods. As this could not be done, investigation of the nitrogen metabolism was limited to estimations of VOL. 4, 1946] 
nitrogen in the excreta over short periods while the patient was on a constant diet with or without the addition of hydrolysate. The results gave an approximate figure for the absorption of the added nitrogen in the hydrolysate.

The first patient, a woman who had been admitted previously in incipient tetany with gross steatorrhoea and clinical signs of vitamin deficiency, was in fairly good condition when therapy was started, except for a moderate macrocytic anaemia, which had responded to purified liver extract (anahaemin). The patient was now showing a severe local reaction to the liver preparation. She had not been treated with autolysed yeast. The papain digest of beef was given in $500 \mathrm{ml}$. portions daily for 4 days. This represented an addition of $5.9 \mathrm{~g}$. of nitrogen a day, of which approximately 50 per cent. was absorbed. After an interval of 3 days, the digest was given again for 3 days. At the end of this period the anaemia showed no response.

The second patient, a woman who had been under observation and treatment at intervals for 3 years, showed a typical idiopathic steatorrhoea, with bouts of tetany responding to calcium chloride by mouth combined with ultraviolet irradiation. She also had shown clinical signs of vitamin $B$ deficiency, and a vitamin $B_{1}$ deficiency was proved by an excretion test. The avitaminosis responded -well to therapy, and at the beginning of the present observations she was in fair condition except for a macrocytic anaemia, which did not respond to purified liver extracts or marmite, and gave only a doubtful response to a crude liver extract given orally. She was given $15 \mathrm{~g}$. of casein digest a day orally for a week, and then $20 \mathrm{~g}$. daily for a further 4 days. This hydrolysate was well tolerated, and the general condition improved, but the anaemia showed no response to this therapy.

The third case was a girl of 15 who had been under treatment for coeliac disease for 12 years. When admitted to the metabolic ward 18 months ago she was dwarfed, $4 \mathrm{ft} .2 \mathrm{in}$. in height, had late rickets, and a typical fatty stool showing many undigested muscle fibres. The general condition improved under treatment, but the child failed to grow, and one year later the height was the same. She was treated as an out-patient, and given $25 \mathrm{~g}$. of casein hydrolysate per day orally. At the same time she was receiving injections of purified liver extract (anahaemin). The hydrolysate was taken fairly regularly for 8 weeks, at the end of which time the condition was the same; there had been a slight increase in weight, but no growth, and the anaemia was unchanged.

The fourth case was a boy admitted 20 months ago, aged 15 . He was very similar to the previous case. His height was 4 feet 2 inches. The condition reacted well to therapy with calcium chloride, ultraviolet light irradiation, and vitamins, but he did not grow and a year later his height was still the same. He was then given $500 \mathrm{ml}$. of a papain digest of meat daily for 3 days, when approximately the whole of the $5.4 \mathrm{~g}$. of nitrogen in the digest was absorbed, and $1 \cdot 2 \mathrm{~g}$. was excreted in the urine. Three months later the height was 4 feet $2 \frac{1}{2}$ inches, and there was an increase in weight. He was then given $35 \mathrm{~g}$. of casein hydrolysate orally each day for 12 days in hospital, and afterwards treated as an out-patient, when he continued to take approximately $35 \mathrm{~g}$. of the hydrolysate per day until he had consumed $3 \mathrm{lb}$. of hydrolysate. Eight weeks after 
starting to take the casein digest, his height was 4 feet $3 \frac{1}{2}$ inches, and 6 weeks later 4 feet $4 \frac{1}{2}$ inches; by now he was complaining that his feet were getting too big for his shoes. In 3 months he had grown 2 inches. While bearing in mind the fallacy of post hoc, ergo propter hoc, one may postulate that this sudden growth had been stimulated by the administration of amino-acids.

Reviewing the results of the administration of hydrolysates to these four patients, one may state that, while the hydrolysate was well tolerated when given by mouth as a supplement to dietary treatment, and did not cause any intestinal upset, in only one case, that of the dwarfed boy, was it accompanied by any real improvement in the condition, and that the refractory anaemias did not respond at all.

\section{Summary}

From published reports, personal experience, and verbal communications, I can draw the following tentative conclusions as to the therapeutic value of protein hydrolysates. Intravenous alimentation with these substances appears to be of most value in conditions such as burns, where the protein loss is excessive, and the requirement to balance this loss is larger than can be made up by feeding the protein itself, or in pre- or post-operative cases where for mechanical reasons the ingestion of protein by mouth is prevented or limited.

While the published reports on the treatment of gastro-enteritis in infants are favourable, experience in Glasgow does not point to any advantage in hydrolysate therapy for these cases, as far as one can ascertain from personal communications.

The use of hydrolysates in starvation does not seem to have any great advantage over other methods.

Oral administration of casein digests except by tube feeding has been disappointing owing to their flavour, and meat digests are much to be preferred for this route.

Hydrolysate therapy is as yet in its infancy, and no doubt time will show its real value.

\section{REFTRENCES}

Adamson, A. C. and Lewes, D. (1944). Brit. med. J. ii, 370.

Altshuler, S. S., Sahyun, M., Schneider, H. and Satriano, D. (1943). J. Amer. med. Ass. 121, 163.

Anderson, A. B. and Semeonoff, E. (1944). Spec. Rep. Ser. med. Res. Coun., Lond., no. 249 , p. 166.

Beattie, J. and Marshall, J. (1944). Nature, Lond., 153, 525.

Brunsehwig, A., Clark, D. E. and Corbin, N. (1942). Ann. Surg. 115, 1091.

Burger, G. C. E., Stanstead, H. R. and Drummond, J. (1945). Lancet, 249, 282.

Cole, S. W. and Onslow, H. (1916). Lancet, ii, 9.

Cope, D., Nathanson, I. T., Rourke, G. M. and Wilson, H. (1943). Ann. Surg. $117,937$.

Co Tui, Wright, A. M., Mulholland, J. H., Barcham, I. and Breed, F. S. (1944). Ann. Surg. 119, 815.

Curreri, A. R., Hibma, D. V. and Cohen, P. P. (1945). J. Amer. med. Ass. 128, 732.

Cuthbertson, D. P. (1944). Brit. med. Bull. 2, 207.

Elman, R. (1942). J. Amer. med. Ass. $120,1176$.

Elman, R. (1943). Amer. J. digest. Dis. 10, 48.

Elman, R. (1944). Physiol. Rev. 24, 372.

Elman, R. (1945). J. Amer. med. Ass. 128, 659.

VOL. 4, 1946] 
Elman, R. and Weiner, D. O. (1939). J. Amer. med. Ass. 112, 796.

Elman, R., Weiner, D. O. and Bradley, E. (1942). Ann. Surg. 115, 1160.

Gaunt, W. E. (1944). Nutr. Abstr. Rev. 13, 501.

Hartmann, A. F., Lawler, H. J. and Meeker, C. S. (1944). J. Pediat. 24, 371.

Hill, L. W. (1941). J. Amer. med. Ass. 116, 2135.

Hopps, H. C. and Campbell, J. A. (1943). J. Lab. clin. Med. 28, 1203.

Krishnan, K. V., Narayanan, E. K. and Sankaran, G. (1944). Indian med. Gaz. 79,160 .

Lipscomb, F. M. (1945). Lancet, 249, 313.

Lucido, J. (1940). Ann. Surg. 111, 640.

Messinger, W. J. (1943). Archi. intern. Med. 72, 91.

Narayanan, E. K. and Krishnan, K. V. (1944). Indian med. Gaz. 79, 158.

Neumeister, R. (1889). S.B. phys.-med. Ges. Würzburg, p. 64.

Olmsted, W. H., Harford, C. G. and Hampton, S. F. (1944). Arch. intern. Med. $73,341$.

Shohl, H. T. (1943). J. clin. Invest. 22, 257.

Taylor, F. H. L., Levenson, S. M., Davidson, C. S., Browder, N. C. and Lund, C. C. (1943). Ann. Surg. 118, 215.

Vaughan, J., Dent, C. and Pitt-Rivers, R. (1945). Proc. R. Soc. Hed. 38, 395.

\section{Use of Isotopic Tracers in the Study of Protein Metabolism}

Mr. H. D. Griffith (Department of Natural Philosophy, University of
Aberdeen)

\section{The Technique and its Limitations}

Since the first application of isotopic analysis to biological problens by Hevesy (1923) in collaboration with Paneth, isotopes of a very wide range of elements have become available (see Seaborg, 1944). Those which have been used to study protein metabolism include stable isotopes of hydrogen, carbon, nitrogen, oxygen and sulphur, and radio-active isotopes of carbon, sulphur and phosphorus. An experiment by Foster, Schoenheimer and Rittenberg (1939), in which $\mathbf{N}^{15}$ was used, may be quoted in illustration of the sort of technique involved. The problem concerned the fate of ingested ammonia. In normal ammonia, as in all normal nitrogen compounds, 0.368 per cent. of the nitrogen atoms are of the "heavy" species; by special methods, discussed later, a sample of ammonium citrate was prepared containing 1.578 per cent. of its nitrogen as $\mathrm{N}^{15}$, that is, $1 \cdot 21$ per cent. "excess" $\mathrm{N}^{15}$. This material was fed to rats; the urinary bippuric acid was isolated, and was found to contain 0.045 per cent. excess $\mathrm{N}^{15}$, i.e., 0.413 per cent. of its nitrogen was $\mathrm{N}^{15}$. The conclusion was that 0.045 out of 1.21 parts of ingested ammonia, or about 3 to 4 per cent., was excreted as hippuric acid. Two great advantages of the isotopic technique should be noted. It was not necessary to isolate all the hippuric acid excreted; all that was required was to secure a small pure specimen, sufficient to yield about $1 \mathrm{mg}$. of total nitrogen; moreover, unequivocal information was obtained as to the fate of the ammonia which was fed, though most of the hippuric acid found in the urine came from other sources.

If a radio-active isotope is employed, the technique is similar, but detection and estimation of the isotope in the final product is by physical tests for the emitted radiation using particle counters or ionization 